From the head of navigation on the Rhine to the sea, the distance is 445 miles. Therefore the Mississippi offers a water outlet to a far more extensive region than does the Rhine; and the potential wealth of the American domain is infinitely greater and in some respects more varied."

\section{Cold-Storage Plant in Madrid}

WI'TH the aid of cold-storage plant it is possible to regulate the supply of perishable foodstuffs to a city so that, whatever the season, the supply may be sufficient. A privately owned cold-storage building has been erected in Madrid with this end in view. 0 . Rhunke gives a description of the plant used in this building in the Escher-Wyss News of April. A five-storied building was constructed in the immediate vicinity of the principal markets, with the railway track on one side and the Calle de Toledo on the other. The level of the railway is $23 \mathrm{ft}$. above the level of the street, so that goods are unloaded from the railway into a chute and delivered into the street from the ground floor. Ten thousand cubic metres are provided for storage for eggs, fruit and fish. The main cooling is by conditioned air with brinecirculated cooling in addition. The temperature and humidity of all the cooling rooms have to be kept within prescribed limits. The used air is cleared out several times every day and ozonising is employed. Special care has to be taken to prevent any interruption of the cooling process taking place. A cooling capacity of thirteen million British thermal units per day is required. It was at first thought that such a spacious building would considerably exceed the needs of the city, but three months after the opening practically all the space was utilised.

\section{East Malling Research Station}

THe twenty-second annual report, for the year 1934, of the East Malling Research Station, has just been published (pp. 241. 4s. net. May 1935). The Station is maintained by the Kent Incorporated Society for Promoting Experiments in Horticulture, with various grants from the Ministry of Agriculture and Fisheries. A 22-page supplement describes the more administrative side of the Station, and leaves the main volume free to set forth the research findings during the past year. These are, perhaps, even more numerous than usual, for a determined effort has been made to elucidate more fully the problems of insecticides and fungicides. Section 1 of the report describes the experimental farm, and is contributed by Messrs. J. Amos, F. H. Beard, M. H. Moore and A. C. Painter, with a foreword by the director, Mr. R. G. Hatton. Section 2 is a general review of research work, with summaries of papers published during the year. It is compiled by numerous members of the staff. The third section, on preliminary research reports, occupies most of the volume. Truly is the East Malling Research Station justifying its comparison, voiced by H.R.H. the Duke of York, to a standard apple tree, which, once established on good soil, would "continue to flourish and yield excellent fruit".

\section{Farm Machinery}

The favourable reception that attended the publication of the first volume of "Farm and Machine" issued by the Institute for Research in Agricultural Engineering, Oxford, last year, has led to the decision that an annual issue would be justified. Vol. 2, which has recently appeared (2s. 6d.), contains like its predecessor the report of the Institute for the year under review and also a collection of miscellaneous papers on agricultural engineering. The chief event of the year has been the removal of the Institute into its new quarters in Parks Road, a building well suited for the indoor work and provided with excellent workshop and stores accommodation. The testing of various new types of agricultural machinery naturally takes a prominent place in the work of the Institute, but research on the theoretical side is also carried out, from which important advances have already been made. The titles of some of the miscellaneous articles such as market garden tractors, farm electricity tariffs, the mode of action of mole drains, sugar beet harvesting, implements for regenerating grassland need only be quoted to show that the volume is likely to be of help and interest to a wide section of the farming community.

\section{Rare Developmental Condition in a Boy}

A note by Science Service, of Washington, D.C., states that a 'dog-boy' four years old is living in Kharkov, U.S.S.R. His face and body are entirely covered with long blond hair, coarse and a little wavy. The child is otherwise normal mentally and physically except for rickets, which is being treated in the hospital. The relatives are all normal so far as known. This very rare condition is known as hypertrichosis universalis. Some thirty such families have been recorded, most of them from Russia. In certain cases reported from India, the hair was dark. The condition is a developmental defect, in which the prenatal lanugo is not shed. It may be accompanied by faulty teeth and nails. Once the condition has appeared, it is likely to recur in the next generation. An effort should be made to determine whether the family producing this child is related in any way to the previously recorded Russian families.

\section{Bibliography of Seismology}

IN a recent issue of Nature (135, 1070 ; June 29), a brief notice was given of the "Bibliography of Seismology" for the year 1934 prepared by the Dominion Observatory of Ottawa. In that note, it was pointed out that Great Britain is not represented in the list of collaborators. We have received a letter from Dr. F. J. W. Whipple, Kew Observatory, in which he suggests that this omission may be taken to imply that the works of British seismologists are ignored in the Bibliography, and he states that in the last quarterly number there are seven references to such publications. On the other hand, in the United States, there are eleven collaborators, who refer to forty memoirs written in that country. The test as regards completeness is not, however, the actual number of memoirs noticed, so much as the 